\title{
Single Beat JTCB Interval
}

National Cancer Institute

\section{Source}

National Cancer Institute. Single Beat JT CB Interval. NCI Thesaurus. Code C117764.

A JTSB interval corrected for heart rate using Bazett's formula. (CDISC) 